\title{
The Redemption of the Soul with Simplicity and Affectionateness in 'Paths of the Soul' Film
}

\author{
Zhu Junwei \\ Henan Institute of Economics and Trade, Henan, China, 450018 \\ Keywords: National character; Redemption; Faith \\ Abstract: The eleven people in 'Paths of the Soul' film is not afraid of any difficulties and \\ obstacles in the all way to west. They are neither angry and neither humble nor arrogant to \\ complete the soul of salvation with a calm and pious heart. The movie struck a chord with \\ everyone's unconscious. It's a slightly exaggerated take on the solemnity of pilgrimage, as \\ the director had made us a bowl of summer chicken soup. There's a lot of subconscious \\ dialogue, so it's a complicated process of acceptance. However, there is no documentary \\ that is absolutely true. In some preconceived illusions, every audience has to understand \\ the pilgrimage they see.
}

I pray for people all the way from my hometown. I used to drink too much and live a lazy life. After the pilgrimage, I will try my best to do good deed. I will pray for the welfare of all living beings in front of the Buddha statue in Jokhang Temple. I will live like that with or without hell.

Excerpts from an interview with the documentary tea and horse ancient road: pilgrimage road

I go to bed at night thinking that 'Paths of the Soul' is next to my pillow. During the day, I thought that 'Paths of the Soul' was on top of my head. When I prostrated myself, I thought that 'Paths of the Soul' could eliminate the sickness on his body and the pain in his heart.

Excerpts from an interview with the third pole

\section{Introduction}

Tibet is a place worth exploring forever, and the theme of pilgrimage in Tibet is not new for everyone. A long time ago, it has been shown in the photographic works. Today, many photographers focus their lens on Tibet and the pilgrimage road. In 2008, the six-part documentary "ancient road of tea and horse" was jointly produced by KBS of South Korea and NHK of Japan. The pilgrimage road filmed the pilgrims from Sichuan province, which lasted 185 days and more than 2,100 kilometres. They went through illness and hardship, crawling on their hands and knees, just to get to the Jokhang Temple in Lhasa. They want to be able to worship at the feet of god and pray for life. In 2011, a Taiwanese director made a documentary named "Oriental experience" -- tea and horse ancient road. Episodes 8 and 9 detail the hardships and persistence of the pilgrimage. In 2015, CCTV broadcast the documentary the third pole, which introduced the human geography of Tibet in detail with 40 stories. 


\section{The true feeling in 'Paths of the Soul' Film}

\subsection{The aesthetic power of documentary}

Documentary films about minorities are not minority. Documentary films appeal to us more by the power of real aesthetics. In 2004, the 'Asian Corridor in Heaven' film Shoot along the caravan route. Horse life, the original people are to shoot the masters, which does not set the story and completely true record. The sense of reality is a judgment made on the characters and events recorded in the documentary, rather than a judgment on the viewpoints. Because the life experience is the social knowledge resources, and not the individual opinion or the viewpoint. 'Asian Corridor in Heaven' is different from 'Paths of the Soul'. Wu professor at Beijing film academy, classifies 'Paths of the Soul' as an art film. It is similar in this respect to Robert's film the 'Nanook of the North'. The 'Paths of the Soul' include the elderly, children, young men, pregnant women and so on. At the end of 2013, Zhang led the film crew to select several non-professional actors with good images. They don't use scripts. They spend a year with them, shooting and looking for stories. They met more than a dozen pilgrims on the way and saw many of their true stories, and then added to the film. But in this film we still see a lot of Settings. For example, the birth of a child sets the death of an old person, which is a binary structure of life and death, a process of reincarnation. The pilgrim's mind rose to an ethereal state of meditation.

We've heard a lot about information about Everest, but the name of 'Paths of the Soul', the sacred mountain in the hearts of the pilgrims, has its own mystique. The filming of the third pole started in September 2013, and the filming of 'Paths of the Soul' started at the end of 2013. The filming lasted until the year of the Tibetan horse in 2014, which is the birth year of 'Paths of the Soul'. There is a legend that the pilgrims circle the mountain in the year of the birth of the year is equal to twelve circles in the usual year. Pilgrims began a journey of more than 2,500 kilometre for different purposes. For example, a men is only for the completion will, the butcher for atonement, a father with 9 years old daughter for the dead, and so on. A small team set out to complete the soul of self-salvation. The film tells about the tenacity and perseverance of the pilgrims for one and a half hours, which has a lot to do with the national character. The particularity of the geographical environment live in endows them with distinctive characteristics. Surrounded by mountains, steep terrain and harsh climate, the Tibetan people have been able to survive and thrive in such a harsh environment, and then they have developed their own language, script and civilization. The Tibetan people have a superhuman adaptability to harsh environments. They use painting, dance, singing and other art forms to express the passionate character and desire for freedom.

\subsection{The main plot in 'Paths of the Soul' Film}

The director Zhang yang made a movie about the old topic of pilgrimage and brought up many topics in the summer of 2017, which is very difficult. There are numerous handsome men and beautiful women full of screen in the import blockbuster. Which made many people tired of watching some putrid, mannered performances. However, 'Paths of the Soul' is like a refreshing cold dish on a hot summer day. Which allows one to sit and watch a different type film with a different aesthetic. It gives people a reverse thinking in the fast-paced life. People can spend a year on their hands and knees, walking only a few miles a day for the sake of their faith in 'Paths of the Soul'. We need such works to compare with our own hearts and guard against arrogance and rashness. The lyrics of the theme song are: 'let me feel the pain once more, take it all away and leave me empty-handed again. Only when I am dying can the real me be born.' From this we can see the spiritual catharsis brought by the pilgrimage faith.

Is the movie about perfection? For example, the pregnant woman gave birth to a baby on the way, 
the nine-year-old girl did not hide from the rolling stones, a men died on the way of pilgrimage, and so on. Can 'Paths of the Soul' really bear the weight of this life? A series of questions kept the audience looking forward, and watching every detail of their journey. They didn't claim for the damage to tractor. They were poor farmers, and the driver simply apologized. Is this the real life of The Tibetan people? We go back to the beginning of the movie, in order to make a pilgrimage, a man takes her son to buy rubber shoes and haggles with the peddler. She needs to store food and pay the butcher for slaughtering cattle and sheep. And here's the inscrutable plot, they go on a pilgrimage instead of a saint. For example, they spent 600 on shoes and 200 on refuel. When they arrived in Lhasa, they had to do odd jobs to earn money and kowtow to the landlord for payment. Many places told them that they needed money on their pilgrimage.

The film takes us to appreciate the changing seasons in Tibet, such as the wind, rain, snow, mud, Rolling Stones, and sunshine. They are not afraid of any difficulties and dangers all the way west, like on the way to the ninety-nine eighty-one difficult. When there is a danger or happy we face together, with keeping a calm, not angry, not humble not arrogant treat pious heart. Eleven people make a pilgrimage like an ascetic, and the journey of 2,500 kilometre is also a journey in everyone's mind. The film conveys their personal feelings of pilgrimage. Everyone has problems on the road, and they are a whole with supporting and encouraging each other, praying together, and facing difficulties together. When the locomotive was smashed, they pulled the caravan up the hill and sang together. I walked to the top of the mountain step by step, snow to the earth bit by bit, in the snow and I met the place, I think of my mother. Although the song had no background music to ignite the climax, it was so powerful. When a big car passed by, they never asked for help, because they knew the road under their feet had to be walked out step by step. The new born boy lay in the car waving his hands as if saying "go, go, go". Actually everyone has their own personality traits, but now it is a perfect unity, this set of shots is really touching. At this point, the film resonates with the collective unconscious. From a certain point of view, the charm of film art lies in its individual or collective unconscious mining. The audience's resonance with the screen is often because the characters in the film resonate with the audience, which is the awakening of a remote, primordial memory. Film art has a lot of subconscious dialogue and psychological resonance. So it's a complicated process of acceptance, but there's no absolute documentary. In some of the preconceived illusions, each viewer has to make sense of the pilgrimage they see.

\subsection{My true feelings about Tibetan pilgrimage culture}

I have been in contact with the Tibetan people. I have heard about the fierce Tibetan men before. I chatted with a Tibetan woman selling specialty products for a few minutes. She introduced specialty products and prices carefully, and I felt that she was very enthusiastic. The Tibetan people are a religious people who are used to a slow lifestyle and slow to accept new things. Facing the special geographical environment and the dangers of the mountains, they have a strong sense of awe. The economy is underdeveloped, and it prevents their minds from expanding. Here a lot of things are decided by divination, praying that the mountain god can bring good luck and health. The Tibetan mountain god worship culture has experienced the fusion of Buddhism and Buddhism. The sacred mountain genealogy embodies the history and culture of Tibetan tribes. It is not surprising that they spend a year crawling more than 2,500 kilometre to reach the 'Paths of the Soul' mountains instead of earning money to support their families and develop their economy. There are many things in movies that we can't understand in our own way. In fact, 'Paths of the Soul' in the account of the pilgrimage behind the story, and did not go beyond the documentary 'Asian Corridor in Heaven'. Which may be one of the differences between a film and a documentary. The film leaves the audience is thinking, while the documentary explains the origin of things in detail. 


\section{The Redemption of the Soul in 'Paths of the Soul' Film}

\subsection{Soul belonging and identification}

In the eyes of the Tibetan people, their souls are always close to the Buddha. Through daily prayer, and finally the pilgrimage, the spirit of belonging is their life. The present Tibetan Buddhism absorbs the essence of the bon religion and Indian Buddhism, and then it forms a situation of universal belief in Tibetan areas. Religion is when people can't explain some phenomena, and then they personify them through ghosts and gods and worship them. First, bless yourself or your family. Second, find spiritual sustenance. The Tibetan people are cautious and cautious. They never talk loudly, and do not kill animals. This culture has been inherited, and the great cultural identity has formed the unique Tibetan Buddhism.

\subsection{Self-redemption of the soul}

The precepts of Buddhism clearly stipulate that no drinking is allowed, but a man always drinks too much. So, he embarked on a pilgrimage of self-salvation. He abstained from drinking on his pilgrimage. There is a scene in the film where he is kowtowing and finds a little bug in front of him. Instead of kowtowing, he waits for the bug passing. Self-salvation is not something that can be achieved by completing a pilgrimage. It can be found in the little things of daily life. Tibetans perfectly integrate their personal life with religious beliefs. Their daily behaviors and actions are influenced by religious beliefs. In daily life, they can worship and pray as well as living on the pilgrimage road.

\section{Conclusion}

Nowadays, with the rapid development of economy, people living in big cities are faced with integrity problem while living a superior life. People have been confused and doubted. Instead, unkempt people living in poor areas are unsophisticated and kind-hearted. Is it because they have no knowledge, no culture and no sense of self? Some people think that modern civilization has not entered these poor areas, pilgrimage is just a superstition. Of course, pilgrimage is a religious belief and their historical heritage, but should not be deified. Because highly educated The Tibetan peoplewith education gradually weaken the pilgrimage.

'Paths of the Soul' is still a spiritual symbol for the Tibetan people, a sacred mountain where everyone is willing to give. They would rather give up their lives than their faith, which is my intuitive feeling after watching the movie. The film reflects the character of the Tibetan people. There is no denying that national character is one of the highlights of national films. Tibetan culture and spirit infected us, they walked on with the snow.

\section{References}

[1] Zhang tongdao. multiple symbiosis record space and time [M]. Beijing normal university press, page 7, 2010.

[2] Chang lixia, Cui mingde. Worship of Tibetan mountain gods and their symbols [N]. Journal of south-central university for nationalities, July 2012.

[3] Chen xuguang. Noumenon and dimension of art [M]. Peking University press, page 309, January 1, 2017. 